\title{
Vein of Galen Aneurysmal Malformation with Transvenous Endovascular Treatment in an Adult: Case Report
}

\section{Malformação aneurismática da veia de Galeno com tratamento endovascular transvenoso em adulto: relato de}

\section{caso}

João Lima Cícero Vale ${ }^{1}$ Benjamim Pessoa Vale ${ }^{2}$ Lívio Perreira de Macêdo ${ }^{1}$

Marx Lima de Barros Araújo ${ }^{3}$ Thiago Moraes Sousa ${ }^{1}$

${ }^{1}$ Faculdade Integral Diferencial, Teresina, Piauí, Brazil

${ }^{2}$ Neurosurgery, Endovascular Neurosurgery - Instituto de

Address for correspondence João Lima Vale, Faculdade Integral

Neurociências and Hospital São Marcos, Teresina, Piauí, Brazil

${ }^{3}$ Neurology, Interventional Neurology - Instituto de Neurociências and

University Hospital of Universidade Federal do Piauí, Teresina, Piauí, Brazil

Diferencial, Teresina, Piauí, Brazil (e-mail: joao09cicero@gmail.com).

Arq Bras Neurocir 2017;36:251-255.

\begin{abstract}
Keywords

- vein of Galen aneurysmal malformation

- median prosencephalic vein

- transvenous endovascular treatment

- cerebral veins

Resumo
Palavras-chave
- malformação
aneurismática da veia
de Galeno
- veia prosencefálica
mediana
- tratamento
transvenoso
endovascular
- veias cerebrais

Vein of Galen aneurysmal malformation (VGAM) is the result of the direct communication between the arterial network and the median prosencephalic vein. It is a rare vascular congenital malformation representing less than $1 \%$ of intracranial abnormalities. This finding is very rare in adults, and it may or may not present symptoms during childhood. Most cases of VGAM can be detected in the fetus by ultrasonography. The referral of pregnant women with fetuses with this condition to centers where better facilities and resources for childbirth and immediate postpartum care are available has resulted in considerable improvement in the prognosis of newborns. Regarding treatment, the endovascular approach to VGAM includes arterial embolization and percutaneous transvenous techniques. The transvenous endovascular treatment was chosen in the case presented in this article.

A malformação aneurismática da veia de Galeno (MAVG) é resultado da comunicação direta entre a rede arterial e a veia prosencefálica mediana. Trata-se de uma malformação vascular congênita rara, que representa menos de $1 \%$ das anormalidades intracranianas. Sua ocorrência é muito rara em adultos, e a malformação pode ou não apresentar sintomas durante a infância. A maioria dos casos pode ser detectada em fetos por ultrassonografia. O encaminhamento de grávidas com fetos com esta malformação para centros mais bem estruturados, com recursos para cuidados no parto e pós-parto, tem resultado em considerável melhora do prognóstico de recémnascidos. Quanto ao tratamento, o acesso endovascular à MAVG inclui a técnica de embolização arterial e o tratamento transvenoso percutâneo. O tratamento transvenoso endovascular foi escolhido no caso apresentado neste artigo.
\end{abstract}

received

June 26, 2017

accepted

August 24, 2017

published online

October 11, 2017 


\section{Introduction}

The great cerebral vein, also known as Galen vein, is a very important component of the cerebral drainage system, receiving the entire venous blood supply of the internal and basal cerebral veins; along with the inferior sagittal sinus, it drains to the straight sinus.

Vein of Galen aneurysmal malformation (VGAM) is the result of the direct communication between the arterial network and the median prosencephalic vein. ${ }^{1}$ Based on the observation of the angioarchitecture of this lesion, Raybaud et al concluded that the abnormal development of this malformation occurs mainly between the 6th and 11 th weeks of intrauterine life, after the development of the circle of Willis. ${ }^{2,3}$ These researchers also believe that the fact of fetal anatomic remanence that produces frequent occlusions in the posterior fossa, the dural sinuses, especially in the sigmoid sinus. This can be one of the reasons for the higher prevalence of this disease in children. ${ }^{2-4}$

Due to the fact that the VGAM is mostly a congenital vascular malformation, the widespread use of ultrasound in the prenatal routine enabled the early detection of several cases on the third quarter of pregnancy. ${ }^{4}$ Nevertheless, beyond the identification of this abnormality and the differentiation between VGAM and other non-vascular lesions, ultrasonography also helps assess the fetal cardiovascular system, especially for heart failure, which is a main abnormality that accompanies VGAM. ${ }^{5,6}$ Thus, fetal echocardiography also plays a key role in confirming the diagnosis of VGAM in the fetus. ${ }^{7}$

Therefore, VGAM should be strongly considered as a differential diagnosis of heart failure in the first week of life. ${ }^{5}$ The referral of pregnant women with fetuses with this condition to centers where better facilities for childbirth and immediate postpartum care are available resulted in considerable improvement in the prognosis of newborns. ${ }^{4}$

\section{Case Report}

An 18-year-old male patient presented to our institution in November 2003 with a history of headache, visual and behavioral disorders, and learning disabilities. Regarding the pathological history, the patient was submitted to a treatment for VGAM when he was 7 years old. At that moment, he was treated in the city of São Paulo, Southern Brazil, and evolved with clinical improvement, but no medical follow-up was performed.

Upon a mental examination, psychomotor agitation and difficulty to connect ideas were evidenced. Furthermore, a neurological examination showed exalted reflexes and no associated motor deficit.

Thus, an angiography was requested, and it showed the recurrence of the VGAM (-Fig. 1 and - Fig. 2). Then, we opted for endovascular venous embolization. The treatment consisted of occlusion of the vein of Galen by a transvenous route, aided by a guiding arterial catheter.

The procedure was performed with the patient under general anesthesia, using the retrograde Seldinger technique,

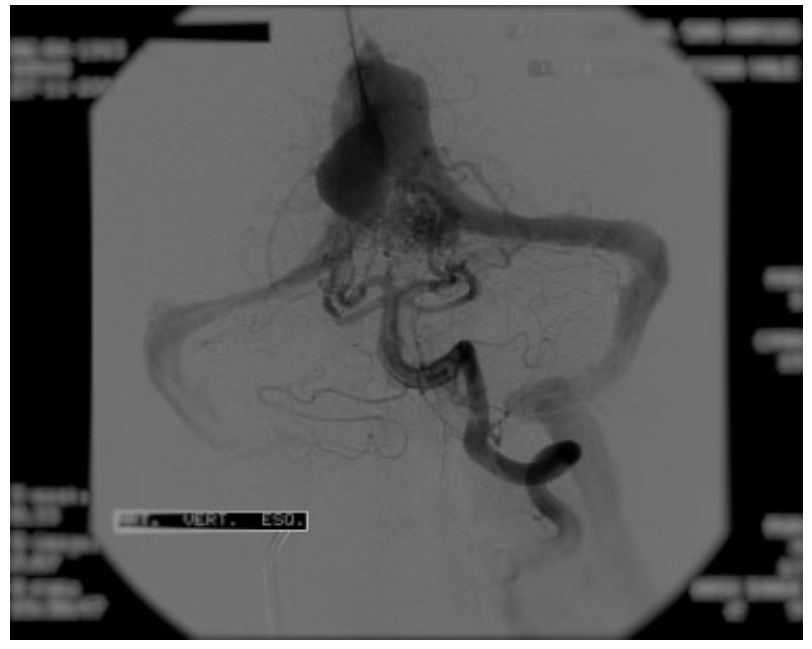

Fig. 1 Digital angiography. Anteroposteior incidence, with the left vertebral artery, evidencing the VGAM.

and the right femoral access was chosen. Using a 5F ENVOY guiding catheter, the right posterior cerebral artery was selectively catheterized combining the Excel 14 microcatheter (Target Therapeutics/Boston Scientific, Fremont, CA, US) and the Transend microguidewire (Stryker Neurovascular, Fremont. CA, US). A post-procedure angiogram revealed complete occlusion of the fistula and better visualization of the posterior cerebral artery branches (-Fig. 3, -Fig. 4 and - Fig. 5).

After approximately seven months, we performed the follow-up of the patient by angiography. It showed no new bleeding and no changes regarding the intervention. Therefore, we considered the procedure successful (-Fig. 6).

\section{Discussion}

In the historical context of the discovery of VGAM, in the II century A.D., Galen described in an animal a deep vein structure behind the third ventricle that today bears his name. In 1937, VGAM was first explicitly described by Jaeger,

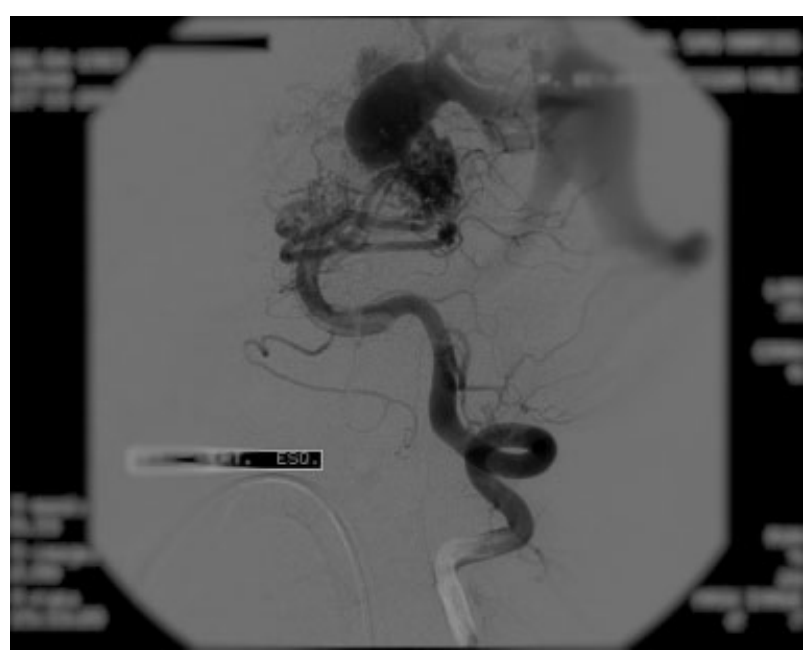

Fig. 2 Digital angiography of the left vertebral artery, incidence in lateral, demonstrating aneurysmal dilatation. 


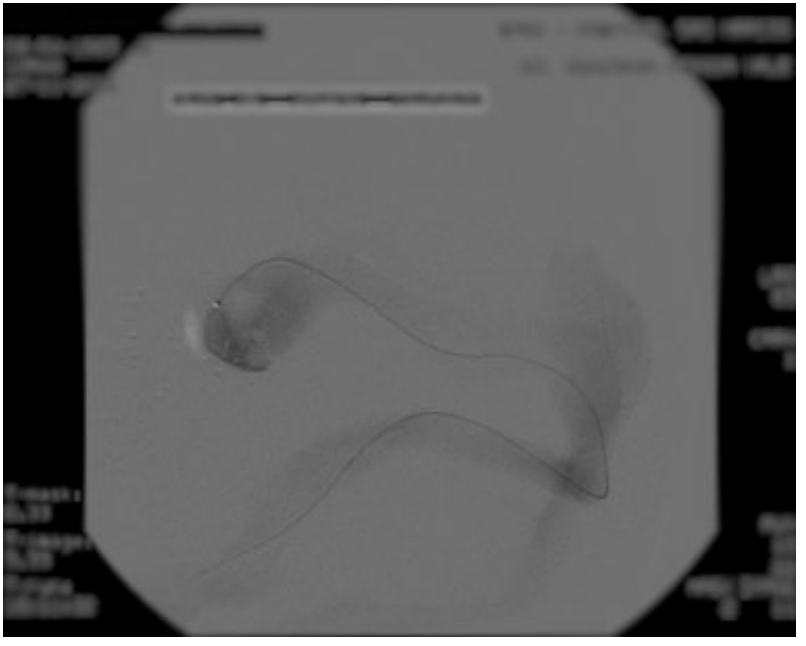

Fig. 3 Microcatheter in a VGAM by the transvenous route.

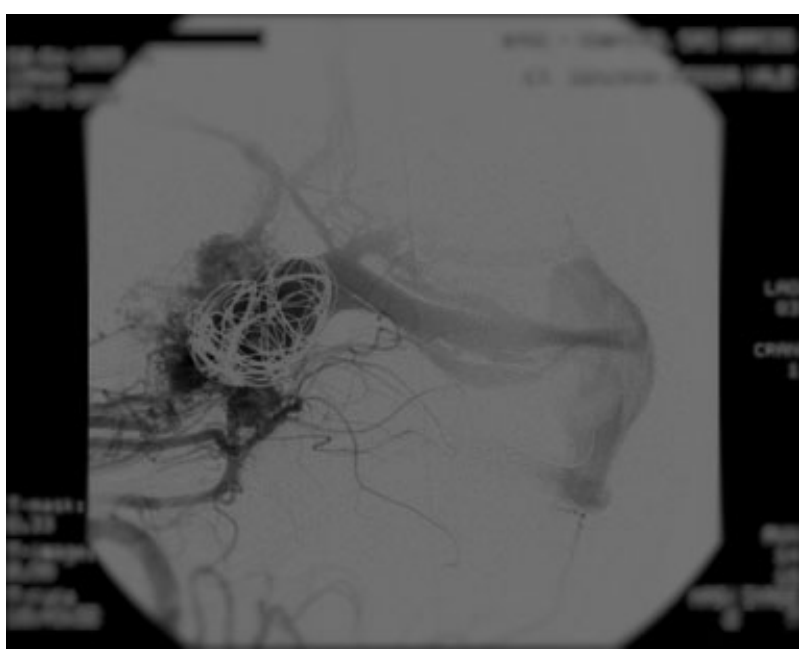

Fig. 4 Embolization of the VGAM with the placement of a microwire through the microcatheter.

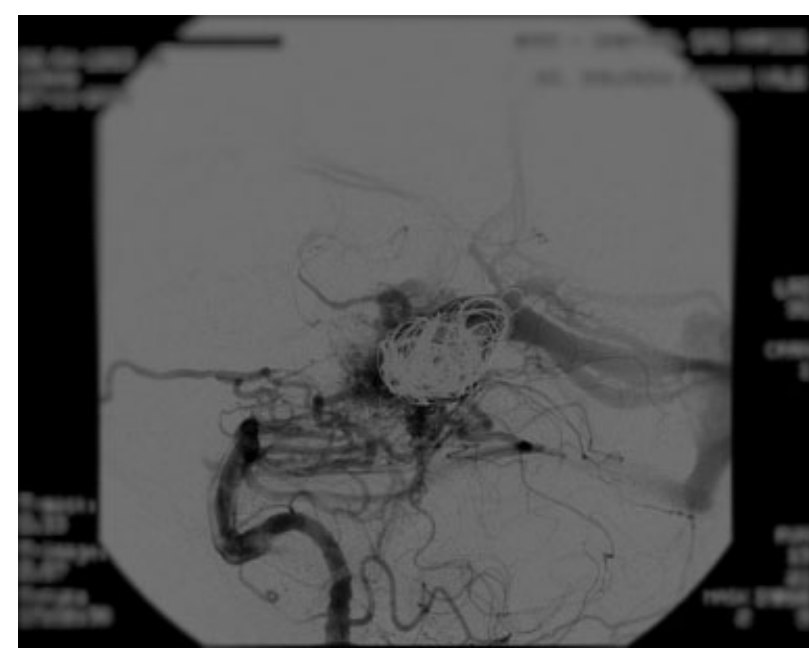

Fig. 5 Occlusion of the VGAM with the placement of a microwire.

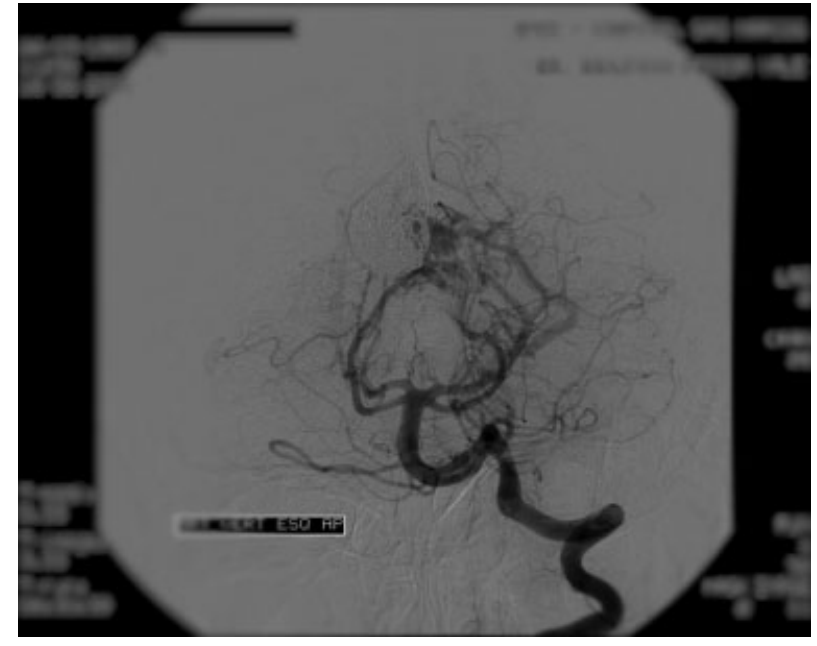

Fig. 6 Follow-up after the endovascular treatment, demonstrating the success of the procedure.

Forees and Dandy. In 1949, carotid angiography was used for the first time in this pathology. In 1953, Gillingham emphasized the indispensable use of spinal angiography in this pathology. ${ }^{8}$

Regarding the embryological aspect, the median prosencephalic vein of Markowski, which is an extracerebral venous blood collector, is the precursor of the vein of Galen. Between the 6th and 11th weeks of intrauterine life, during normal brain development, this vein involve partially in its cranial section to the junction with the internal cerebral venous system. When this regression does not occurs, the vein of Galen is fueled by the choroidal arteries, and expands gradually until it gives rise to a VGAM. ${ }^{4,9}$

Several different classifications were made to describe these abnormal arteriovenous fistulas involving the Galen vein. The two most commonly used are those proposed by Lasjaunias $^{10,11}$ and Yasargil. According to Lasjaunias et al, VGAMs are subdivided into two types: choroidal and mural VGAMs. In the choroidal type, there are multiple fistulas that communicate with the dilated median prosencephalic vein. On the other hand, in the mural type there is an arteriovenous fistula in the wall of the median prosencephalic vein. The choroidal type is more common than the mural type. Patients with choroidal VGAMs usually present in the early neonatal period with severe heart insufficiency and cranial murmur due to multiple fistulas arising from the choroidal, pericallosal and thalamic perforating arteries. Mural VGAMs usually present later in life, with convulsions, macrocephaly and developmental delay in infancy. The fistulas may be unilateral or bilateral. ${ }^{12}$ In the choroidal VGAM, the arterial network is more complex than in the mural type. Mural VGAMs represent approximately $1 / 3$ of all VGAMs, and they are arteriovenous fistulas in the mural of the median prosencephalic vein. ${ }^{13}$

Yasargil classified these malformations according to their morphology and their arterial supply pattern. Type I (mural VGAM) is composed of a direct anastomosis between the VGAM and the pericallosal arteries and/or the P3 segment of the posterior cerebral arteries (PCAs). Type-II malformations consist of a direct fistula between the thalamic perforating 
arteries (P1 segment of the PCA) and the vein of Galen. TypeIII malformations are a combination of types I and II. Types II and III are known as choroidal VGAMs. Type-IV malformations are simply pial arteriovenous malformations that drain into the vein of Galen (aneurysmal dilatation of the vein of Galen, as described by Lasjaunias et al). ${ }^{12}$

Clinically, VGAMs have different characteristics according to age group. In the postpartum period, VGAM is characterized by multiple fistulas with cardiac manifestations, ranging from asymptomatic cardiomegaly to severe and refractory heart insufficiency. During childhood, the fistula is unique and small, resulting in mild or absent cardiac manifestations. In this age group, the patients usually present with macrocephaly and hydrocephalus, which, if persistent, can lead to delayed psychomotor development. ${ }^{14}$

The clinical manifestations can occur at any age, mainly heart insufficiency, developmental delay, hydrocephalus and seizures. ${ }^{10}$ However, VGAM in elderly patients presents clinically with headache, or, occasionally, subarachnoid hemorrhage. ${ }^{15}$

Although rare, this condition has been described in adults by some authors. Despite what is known from some studies, due to its rarity in this age group, there is not yet enough information about this disease in adults. ${ }^{15,16}$ Nevertheless, oral contraceptives, sickle cell anemia, the postpartum state and aseptic meningitis were described as risk factors related to vein of Galen thrombosis. ${ }^{17-19}$

The main imaging method for the diagnosis of VGAM is digital angiography to assess the relationships between venous drainage and the arteriovenous fistulas. ${ }^{1,4,14,15}$ Overall, in the magnetic resonance imaging (MRI) exam they appear as an isodense or hyperdense pineal mass with minimal and heterogeneous contrast enhancement, mimicking pineal tumors. ${ }^{20}$

In order to effectively treat VGAMs, each case should be analyzed in a specific manner. There is no standard treatment applied universally. However, according to Jones et al, the treatment of VGAM was limited before the development of embolization techniques. The surgical treatment of these malformations was often unsatisfactory, with a mortality rate of up to $90 \%$ after surgery in newborns. The endovascular techniques have increased the chances of a successful treatment of these injuries. Nowadays, procedures using endovascular techniques are considered the best interventions in these cases. The treatment consists of the embolization of the lesions. However, surgery can be indicated in cases of endovascular treatment failure or, more rarely, associated to embolization. ${ }^{1,2,4,10}$

Regarding treatment, the endovascular approach to VGAM includes arterial embolization and percutaneous transvenous techniques.

The transvenous approach to VGAM is made through a jugular or femoral access followed by retrograde catheterization of the venous aneurysm. When this is not possible, direct puncture of the torcular Herophili region through an occipital burr hole, aided by ultrasound guidance, provides an alternative route. ${ }^{21}$ Ultimately, both techniques involve partial obstruction or occlusion of the venous aneurysm with microcoils. Some teams have obtained good results with a transvenous technique, and defend its use as a first line option. In addition, other services prefer the transvenous endovascular treatment as a method of choice because the catheterization of the venous aneurysm may also result in their drilling. Furthermore, transarterial embolization often leads to regression of the component lesion of the VGAM and its associated mass effect. A similar result is less likely to occur with the intravascular method, in view of the nature of the coil pack. It should be noted that, in selected cases, the intravenous approach may enable direct retrograde arterial catheterization, reaching the feeder arteries of the fistulas, and the subsequent removal of the VGAM with n-butyl-2cyanoacrylate (NBCA) or microcoils. ${ }^{22}$

Still, the transvenous endovascular treatment is very relevant and, in some cases, essential. The main indications for the transfemoral venous treatment include the presence of persistent symptoms in spite of transarterial embolization or transtorcular venous treatment in any patient, unsuccessful attempts to perform the transarterial embolization (complicated by catheter fracture), and the inconvenience of transarterial embolization due to a an excessive number of arteries feeding the aneurysm. ${ }^{22,23}$

The transvenous route to the vein of Galen can be performed through a transfemoral approach without surgical exposure of the torcular Herophili region. Thus, the percutaneous transvenous approach offers the advantages of the transtorcular approach, but avoids surgery. As an improvement of this technique, the concept of direct retrograde catheterization of the feeding arteries to the VGAM by a transfemoral venous access was introduced by Philippe Gailloud et al in 2005. ${ }^{22,23}$

\section{Conclusion}

According to Lasjaunias et al, no revascularization is observed during the follow-up if the results of the angiographic evaluation of the patients at 6 months and 1 year are completely normal. ${ }^{11}$ Therefore, if the procedure performed on the patient was successful, the evaluation after approximately six months must contain no changes.

\section{References}

1 Marques RM, Lobão CA, Sassaki VS, Aguiar LR. Vein of Galen aneurysm in an adult: case report. Arq Neuropsiquiatr 2006;64 (3B):862-864

2 Jones BV, Ball WS, Tomsick TA, Millard J, Crone KR. Vein of Galen aneurysmal malformation: diagnosis and treatment of 13 children with extended clinical follow-up. AJNR Am J Neuroradiol 2002;23(10):1717-1724

3 Raybaud CA, Strother CM, Hald JK. Aneurysms of the vein of Galen: embryonic considerations and anatomical features relating to the pathogenesis of the malformation. Neuroradiology 1989;31(02):109-128

4 Gupta AK, Varma DR. Vein of Galen malformations: review. Neurol India 2004;52(01):43-53

5 Mitchell PJ, Rosenfeld JV, Dargaville P, et al. Endovascular management of vein of Galen aneurysmal malformations presenting in the neonatal period. AJNR Am J Neuroradiol 2001;22(07):1403-1409

6 Sepulveda W, Vanderheyden T, Pather J, Pasquini L. Vein of galen malformation: prenatal evaluation with three-dimensional power Doppler angiography. J Ultrasound Med 2003;22(12):1395-1398 
7 Félix L, Souza AR, Queiroz AP, et al. Prenatal ultrasonography in the diagnosis of vein of Galen aneurysm. Acta Med Port 2010;23 (03):505-510

8 Omar M. Anévrysme de l'ampoule de Galien: à propos de 03 cas [thesis]. $107 \mathrm{f}$. Pour l'obtention du doctorat em Médecine Université Sidi Mohammed Ben Abdellah, Faculté de Médecine et de Pharmacie, Fès, 2011

9 Deseure-Marx A. Les Malformations anévrismales de la veine de Galien: à propos d'une série de 9 cas diagnostiqués en anténatal. 22 f. Mémoire pour l'obtention du diplome interuniversitaire d'Échographie Gynécologique et Obstétricale - Université du Droit et de la Santé, Faculté de Médecine Henry Warenbourg, Lille, 2012

10 Lasjaunias P, Ter Brugge K, Lopez Ibor L, et al. The role of dural anomalies in vein of Galen aneurysms: report of six cases and review of the literature. AJNR Am J Neuroradiol 1987;8(02): 185-192

11 Lasjaunias PL, Chng SM, Sachet M, Alvarez H, Rodesch G, GarciaMonaco R. The management of vein of Galen aneurysmal malformations. Neurosurgery 2006;59(05, Suppl 3):S184-S194, discussion S3-S13

12 Ralib A, et al. Vein of galen aneurysmal malformation. Hospital Usm, KubangKerian, Kelantan. Available from: http://www.eimjm.com/ Vol2-No1/Vol2-No1- C5.htm\#_ftn1. Accessed on July 52013

13 Ribeiro VT, Botelho LF, Lopes AC, et al. Choroidal type aneurysmal malformation of the vein of Galen associated with Dandy-Walker malformation in an adult. Acta Med Port 2003;16(03):217-220

14 Lin J, Honório LFO, et al. Malformação da Veia de Galeno: relato de caso. Arq Catar Med 2005;34(Supl. no. 2):83-84
15 Hassan T, Timofeev EV, Ezura M, et al. Hemodynamic analysis of an adult vein of Galen aneurysm malformation by use of 3D image-based computational fluid dynamics. AJNR Am J Neuroradiol 2003;24(06):1075-1082

16 Xavier J, Alves V, Vasconcelos C, Leite A, Cruz R. Aneurysmal malformation of the vein of Galen in adults. Acta Med Port 2003; 16(03):203-206

17 Collins JJ, Fisher WS III. Vein of Galen aneurysm presenting with recurrent aseptic meningitis and subsequent spontaneous thrombosis. Surg Neurol 1990;33(05):325-328

18 Ildan F, Cetinalp E, Bagdatoglu H, Boyar B. Evolution of thrombosis of the vein of Galen in sickle cell disease. J Child Neurol 1993;8 (02):189-191

19 Krenz I, Power KJ. Postpartum thrombosis of the great vein of Galen. Anaesthesia 1990;45(08):643-645

20 Gokhale S, Laskowitz DT. Teaching neuroimages: vein of Galen aneurysm mimicking pineal mass in a young adult. Neurology 2013;80(22):e240. Doi: 10.1212/WNL.0b013e318294b3df

21 Dagklis T, et al. Aneurysm of the Vein of Galen Diagnosed with MRI: case report. Hindawi Publishing Corporation Case Reports in Obstetrics and Gynecology Volume 2013, Article ID 716762, 3 pages

22 Gailloud P, O'Riordan DP, Burger I, et al. Diagnosis and management of vein of galen aneurysmal malformations. J Perinatol 2005;25(08):542-551

23 Dowd CF, Halbach VV, Barnwell SL, Higashida RT, Edwards MS, Hieshima GB. Transfemoral venous embolization of vein of Galen malformations. AJNR Am J Neuroradiol 1990;11(04):643-648 